\title{
Pulse source requirements for OTDM systems
}

Clausen, Anders; Poulsen, Henrik Nørskov; Oxenløwe, Leif Katsuo; Siahlo, Andrei; Seoane, Jorge; Jeppesen, Palle

Published in:

Technical Digest IEEE Laser and Elektro-Optics Society Annual Meeting

Link to article, DOI:

10.1109/LEOS.2003.1251822

Publication date:

2003

Document Version

Publisher's PDF, also known as Version of record

Link back to DTU Orbit

Citation (APA):

Clausen, A., Poulsen, H. N., Oxenløwe, L. K., Siahlo, A., Seoane, J., \& Jeppesen, P. (2003). Pulse source requirements for OTDM systems. In Technical Digest IEEE Laser and Elektro-Optics Society Annual Meeting (Vol. 1, pp. TuY2). IEEE. https://doi.org/10.1109/LEOS.2003.1251822

\section{General rights}

Copyright and moral rights for the publications made accessible in the public portal are retained by the authors and/or other copyright owners and it is a condition of accessing publications that users recognise and abide by the legal requirements associated with these rights.

- Users may download and print one copy of any publication from the public portal for the purpose of private study or research.

- You may not further distribute the material or use it for any profit-making activity or commercial gain

- You may freely distribute the URL identifying the publication in the public portal

If you believe that this document breaches copyright please contact us providing details, and we will remove access to the work immediately and investigate your claim 
TuY2

4:00pm-4:15pm

\title{
Pulse source requirements for OTDM systems
}

\author{
A. T. Clausen (1), H. N. Poulsen (2), L. K. Oxenløwe (3), A. I. Siahlo (4), J. Seoane (5), P. Jeppesen (6) \\ 1, 3, 4, 5, 6: COM, Technical University of Denmark; DK-2800 Kgs. Lyngby; Denmark; atc@ com.dtu.dk \\ 2: Department of ECE, University of California, Santa Barbara, United States; henrik@ece.ucsb.edu
}

\begin{abstract}
A simulation model for investigating the impact of incoherent crosstalk due to pulse tail overlapping is proposed. Requirements to pulse width and Pulse Tail Extinction Ratio introducing a maximum of $1 \mathrm{~dB}$ penalty is extracted.

Introduction

Optical Time Division Multiplexing (OTDM) is an attractive technique to increase the overall capacity of optical communication systems, either as u/tra-high bit rates at a single wavelength $/ 1 /$ or as a combination of Wavelength Division Multiplexing (WDM) and OTDM /2/. In both cases, the modulation format is Return-to-Zero (RZ). The objective of this paper is to extract the requirements for the RZ pulses in terms of Full Width Half Maximum (FWHM) and Pulse Tail Extinction Ratio (PTER).
\end{abstract}

\section{Theory}

In a basic OTOM system, the pulse source is characterised by the pulse shape, pulse width and repetition rate $B$. The emitted puise train is split into ' $N$ ' branches, each containing a modulator and a specific delay, which enables the possibility to interleave the bits from each branch. The OTDM signal will have an aggregated bit rate of NxB. In the receiver the OTDM signal is demultiplexed to the ' $N$ ' individual channels, before $O / E$ converted and processed electronically. If the electrical fields from the pulses are overlapping, either due to the pulse width or due to a finite extinction ratio, the neighbouring channels, upon $\mathrm{O} / \mathrm{E}$ conversion, can deteriorate the demultiplexed channel. The noise terms in the receiver due to this process can be shown to consist of Intersymbol interference (ISI) and interferometric crosstalk /3/. The interferometric crosstalk terms are dependent on the coherence time of the pulse source in the OTDM system. If the delay between the pulses is larger than the coherence time, the interferometric crosstalk terms will vary fast, and can be regarded as noise, and is denoted incoherent crosstalk /3/.

\section{Model}

The impact of multiplexing the pulses to an OTDM signal has been evaluated by implementing a simulation model. ' $N$ ' identical pulse trains are implemented, each pulse train defined by the pulse shape, the pulse FWHM width, repetition rate and the PTER, see Fig. 1. Each pulse is assigned a random phase, evenly distributed between 0 and $2 \pi$, to simulate the impact of the incoherent crosstalk. The pulse trains are modulated with a $2^{7}+1$ Pseudo Random Bit Sequence (PRBS), delayed and multiplexed. After multiplexing, the OTDM signal is demultiplexed using an ideal square shaped window with infinite extinction ratio before $O / E$ conversion and evaluation using a BER module with optimised threshold level and decision time. From the BER values the power penalty for each channel is calculated. To determine the average penalties for all the channels, the entire system can be recalculated up to 1000 times.

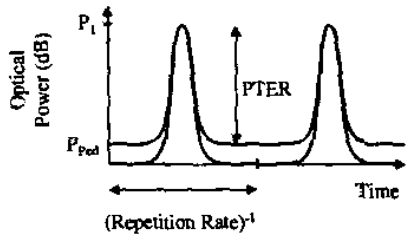

Figure 1: lliustration of a pulse train based on ideal puises and based on pulses with an additional added pedestal, defining the PTER.

\section{Results}

First the impact of multiplexing pulse trains based on ideal pulses, i.e. pulses with no additional pedestal (see Fig. 1), is investigated. As the amplitude of the electrical fields are approaching zero outside the designated time slot, it would be expected that a specific demultiplexed channel would only be affected by the two immediate neighbouring channels, and consequently not limited by the number of OTOM channels. This is confirmed in Fig. 2 where the power penalty for $4 \times 40,8 \times 40,16 \times 40$ and $32 \times 40$ Gbit/s versus the FWHM/Timeslot is illustrated with no significant difference between the introduced power penalties. As opposed to the results in Fig. 2 , the same simulations are carried out for pulse trains based on ideal pulses with an additional added pedestal (see Fig. 1). 


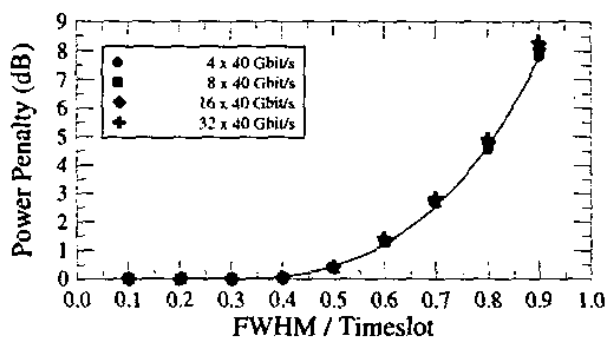

Figure 2: Power penalty for $4 \times 40,8 \times 40,16 \times 40$ and $32 \times 40 \mathrm{Gbit} / \mathrm{s}$ versus the FWHM/Timeslot.
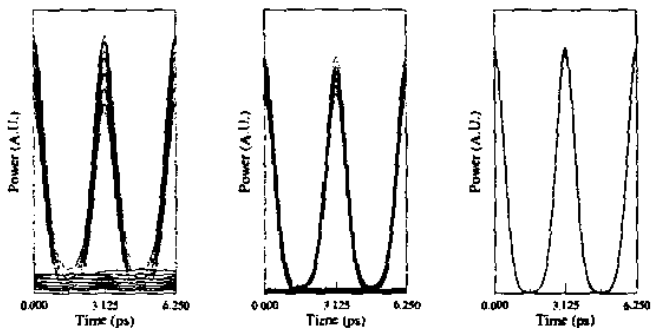

A

B

Figure 3: Eye diagram for 320 Gbits signal based on pulses with $F W H M=0.30 \times$ Timeslot and with PTER of

A) $25 \mathrm{~dB}, \mathrm{~B}) 33 \mathrm{~dB}$ and C) $50 \mathrm{~dB}$.

In Fig. 3 the eye diagrams for an $8 \times 40$ Gbit/s signal are shown for different PTER levels. The FWHM of the pulses are $0.30 \times$ Timeslot corresponding to $\sim 0 \mathrm{~dB}$ penalty for ideal pulses (see Fig. 2). Consequently, the deterioration of the signal is due to an increased impact of incoherent crosstalk for a decrease in the PTER level.

In Fig. 4 the power penalty for $4 \times 40,8 \times 40,16 \times 40$ and $32 \times 40 \mathrm{Gbit} / \mathrm{s}$ is calculated for $\mathrm{FWHM}=0.40$ (A) and 0.50 (B) times the Timeslot. From Fig. 4A the PTER levels introducing a maximum of $1 \mathrm{~dB}$ of penalty is $27,33,37$ and $41 \mathrm{~dB}$ for $160,320,640$ and 1280 Gbit/s respectively. Simulations have confimed that for FWHM $<0.40 \times$ Timesiot, the power penalty is the same for the same PTER. This is in agreement with results in Fig. 2 , where the impact of the ideal pulses is negligible for FWHM/Timeslot $<0.50$. In Fig. 4B the corresponding PTER levels introducing $1 \mathrm{~dB}$ penalty is increased to $29,35,37$ and $43 \mathrm{~dB}$, i.e. the power penalty for a specific PTER level is increased compared to Fig. 4A due to combined impact of both the pulse tails from the ideal pulses and the pedestals. For increased FWHM widths the power penalty for a given PTER is increased even further. It is concluded that the most relaxed requirements for the pulse source is a FWHM $=0.40 \times$ Timesiot and PTER $=27$, 33,37 and $41 \mathrm{~dB}$ for $4 \times 40,8 \times 40,16 \times 40$ and $32 \times 40 \mathrm{Gbit} / \mathrm{s}$, respectively. From the simulations it can be seen that the increase in PTER requirements for increased number of OTDM channels are not directly scalable, e.g. the increase in PTER from 4 to 8 channels compared to an increase from 8 to 16 channels are not identical. This is ascribed to the gradual change of the non-Gaussian shape for the probability density function (pdf) of the incoherent crosstalk towards a Gaussian shaped pdf for an increase in the number of crosstalk terms, i.e. OTDM channels $/ 4$.

A

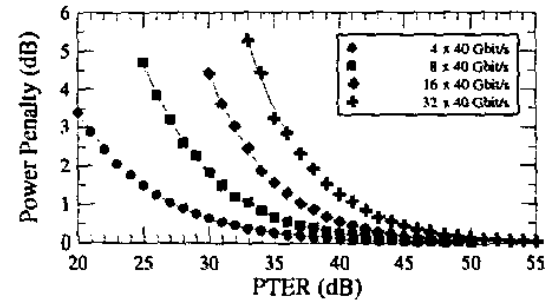

B

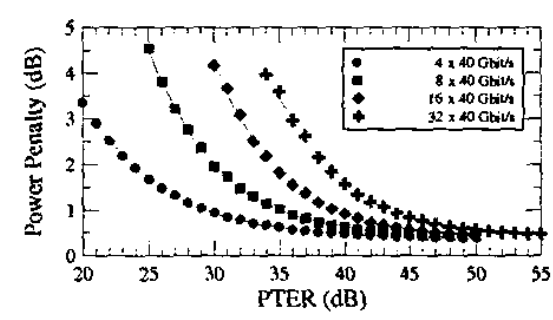

Figure 4: Power penalty versus PTER for pulse width FWHM A) $0.4 \times$ Timeslot and B) $0.5 \times$ Timeslot

\section{Scalability}

The requirements for the pulse source are extracted for an OTDM system based on a base rate of $40 \mathrm{Gbit/s}$. However, the impact of crosstalk is not related to the bit rate but to the number of channels multiplexed together, when assuming the same pulse shape, PTER and same FWHM/Timeslot relation. This has been confirmed in simulations comparing the PTER requirements for a $4 \times 10$ and a $4 \times 40$ Gbit/s system showing identical requirements.

\section{Conclusions}

A model to evaluate the pulse source requirements has been implemented. It is concluded that the most relaxed requirements for the pulse source is a FWHM $=0.40 \times$ Timeslot and PTER $=27,33,37$ and $41 \mathrm{~dB}$ for $4 \times 40$, $8 \times 40,16 \times 40$ and $32 \times 40 \mathrm{Gbit} / \mathrm{s}$, respectively.

\section{Acknowledgements}

This work is partly carried out within the European IST project TOPRATE (IST-2000-28657).

\section{References}

/1/ Nakazawa et al, Elec. Let, Vol. 36 (2000), p. 2027. /2/ Schmidt et al, accepted to ECOC (2003).

/3/ Legg et al, Lightwave Tech, Vol. 14 (1996), p. 1943. /4/ Jiang et al, Proc. OFC (1998), Vol. 3, p. 151. 